\title{
Interpretation, Empiricism, and the Closure Problem
}

\author{
Adrian Vermeule $\dagger$
}

\section{INTRODUCTION}

Should judges adopt formalist doctrines of interpretationthat is, develop interpretive doctrines in the form of rules? ${ }^{1}$ Cass Sunstein's article ${ }^{2}$ outlines a sophisticated and plausible response to this question: The desirability of formalism turns on the answers to a complicated set of empirical and predictive questions about the consequences for institutional performance of choosing alternative doctrines. Will decision costs be higher in a formalist or a nonformalist regime? What about error costs (assuming some suitable definition of error)? Will the adoption of either regime cause a pattern of response by other institutions that will then change the original calculus?

This type of empirical question intervenes decisively between the controlling theory of legitimate authority and the choice of interpretive doctrines. ${ }^{3}$ Any particular theory of authority will often prove compatible with several plausible candidate doctrines, and the election of one candidate will depend upon empirical assumptions, either explicit or implicit. For example, a statutory interpreter who subscribes to an intentionalist theory of authoritystatutes are authoritative because they embody the legislature's intention, and should be interpreted to reflect that intention-cannot reasonably decide, on that basis alone, to consult legislative history as evidence of legislative intent. Rather, the interpreter must first answer, even if only implicitly, a series of empirical and institutional questions: Does legislative history in fact supply

† Assistant Professor, The University of Chicago Law School. Thanks to Beth Garrett, Jack Goldsmith, Jill Hasday, and Eric Posner for comments and suggestions.

1 For this discussion I shall follow Frederick Schauer in equating formalism with rule-based decisionmaking. See Frederick Schauer, Formalism, 97 Yale L J 509, 510 (1988) ('At the heart of the word 'formalism,' in many of its numerous uses, lies the concept of decisionmaking according to rule."). I shall also focus upon statutory interpretation rather than constitutional or contractual interpretation.

2 Cass R. Sunstein, Must Formalism Be Defended Empirically?, 66 U Chi L Rev 636 (1999).

3 Neil Komesar makes this point in the context of institutional choice, see Neil $\mathrm{K}$. Komesar, Imperfect. Alternatives 4-5 (Chicago 1994), and it holds (perhaps a fortiori) for the choice of doctrines to be applied within a particular institution. 
evidence about some suitably specified notion of legislative intent (for example, the understanding of the median legislator) in a broad range of cases? Even if it does, will judges laboring under conditions of limited time and expertise do better at identifying legislative intent with or without legislative history? The answers to these questions will determine whether to adopt rules or standards governing the use of legislative history and what the content of the rule or standard should be.

If the empiricist project is unavoidable within a broad domain, it also holds a two-fold promise: as discussed below, it might enable proponents of various theories of authority to implement their views in the most efficient manner, and also-more ambitiously-might enable them to converge on agreement about particular doctrines without resolving their disputes over first principles. Sunstein, therefore, appropriately calls for more empirical work, as have others, ${ }^{4}$ and there is no question that such work would answer some questions relevant to the choice between formalist and nonformalist interpretive approaches.

But the critical question is how much headway the empiricist project can actually make. The questions on which the choice of interpretive doctrine turns are often empirical in principle yet unanswerable in practice (at least in the short or medium term), given the limitations of our investigative resources, the paucity of available data, and so forth. This is the closure problem: Empirical arguments relevant to the choice between formalist and nonformalist interpretive doctrines may often reduce to a contest of plausible but unconfirmable empirical assertions, with neither side able to close the question out at acceptable cost within a usefully short period of time.

In this Comment I shall first sketch the closure problem more fully, and second consider how the empiricist project can be carried forward in the face of the closure problem. Scholars and judges have used, sometimes implicitly, a handful of strategies that might help us choose interpretive doctrines even under conditions of irreducible empirical uncertainty. One strategy is to allocate the burden of overcoming empirical uncertainty to the proponents or opponents of a given interpretive doctrine, perhaps by creating a presumption in favor of the doctrinal status quo. Another is the "all-else-equal" strategy, which amounts to choosing between doctrines on the basis of ascertainable components of cost even if the unknown components of cost are potentially much

- See, for example, Elizabeth Garrett, Legal Scholarship in the Age of Legislation, 34 Tulsa I J (forthcoming 1999). 
larger. A third strategy is to accord decisive weight to the consensus of the profession, in the hope that many people's estimates about difficult empirical questions will, taken together, approach the truth.

These strategies and others like them are, in the short term at least, what the empiricist project cashes out to mean. There is no cause for criticism here, because empiricism in one form or another is inevitable over the broad range of questions that cannot be answered solely by choosing a normative theory of authority; within this range, legitimacy-based arguments underdetermine doctrinal choice, and interpreters cannot prescribe doctrines without assuming one state of affairs or another. But there is cause to restrain our expectations. The empiricist project is a long-term investment whose immediate returns will prove modest.

\section{THE PROMISE OF EMPIRICAL ARGUMENTS}

In general, the resolution of empirical questions relevant to statutory interpretation promises two types of benefits. The first is efficiency. If the interpreter's theory of authority specifies some appropriate end (say, ascertaining the intention of the median legislator), then that end supplies a benchmark against which various doctrinal options can be measured. For example, one option (say, consulting legislative history) might produce lower decision costs and fewer errors (might correctly divine the median legislator's intent more frequently) than its competitors. Which option will produce the best mix of error costs, decision costs, and so forth is in principle an empirical question once the theory of authority has specified the relevant ends; "best" here just means that that option achieves the same goal more cheaply than the other options do. In this way, the resolution of the relevant empirical questions allows each interpreter's theory of authority to be implemented efficiently.

Second, and more ambitiously, the resolution of empirical questions might enable interpreters holding different theories of authority to converge on particular doctrines. This is a variant of Sunstein's idea of incompletely theorized agreements. ${ }^{5}$ Given certain empirical assumptions, for example, both the proponent of legislative intent and the proponent of ordinary textual meaning might agree upon a rule excluding legislative history. ${ }^{6}$ The inten-

\footnotetext{
s See Cass R. Sunstein, Incompletely Theorized Agreements, 108 Harv L Rev 1733, $1739-45$ (1995).

- See Adrian Vermeule, Legislative History and the Limits of Judicial Competence:
} 
tionalist would agree because, on those assumptions, the rule would minimize both erroneous determinations of legislative intent and the costs of litigation; the textualist would agree because, on the same assumptions, the rule would minimize both erroneous determinations of ordinary textual meaning and litigation costs.

Indeed, empirical closure might even enable interpreters to choose particular doctrines before, or in place of, choosing a theory of authority. If, on certain empirical findings, it turned out that legislative history should be excluded on any plausible theory of the proper aims of interpretation, then as far as that doctrinal question goes there would be no need to choose between the fundamental theories. Of course the set of doctrines that could be the subject of such incompletely theorized agreements might be quite small. But it might also be rather large. Until the empirical questions are answered we cannot know which-and that is an argument for attempting to answer the questions, not for declining to investigate them.

\section{The Closure Problem}

In these respects the potential benefits of answering the empirical questions relevant to statutory interpretation are great. But, for a broad range of questions, the difficulty of obtaining the answers will be even greater. Many of the empirical questions relevant to the choice of interpretive doctrines are "transscientific"-they are unanswerable, at least at an acceptable level of cost or within a useful period of time. ${ }^{7}$ Trans-scientific questions abound not only in the hard sciences but also (or especially) in the social sciences, where the number of variables and difficulty of collecting data often mean that empirical questions never achieve closure, despite seemingly endless study. A familiar example is the superficially simple question whether the death penalty deters crime. "No issue of criminal justice has been subjected to greater empirical study than whether the death penalty is an effective deterrent, and on none is the evidence more ambiguous or conflicting."

The Untold Story of Holy Trinity Church, 50 Stan L Rev 1833, 1862-77 (1998).

' See Alvin M. Weinberg, Nuclear Reactions: Science and Trans-Science 4 (Am Inst of Physics 1992) (Trans-scientific questions are those that "can be asked of science and yet cannot be answered by science. ... [T] [Though they are, epistemologically speaking, questions of fact and can be stated in the language of science, they are unanswerable by science.").

- Dan M. Kahan, The Secret Ambition of Deterrence, 113 Harv L Rev (forthcoming 1999). 
Many of the empirical questions integral to the choice between formalist and nonformalist interpretive approaches appear to share this resistance to closure. Take the apparently simple question whether the total costs of adjudication-including the out-of-pocket costs of litigation, the opportunity costs of judges and lawyers, and so forth-would be higher under a rule that admits legislative history in every case, or instead under a "plain meaning" rule that admits history when, but only when, the text is ambiguous. ${ }^{9}$ The question is empirical but extremely difficult to resolve, for although we can specify (at least some of) the components of the relative cost of the two regimes, the difficult part is to fill in the values of the variables. ${ }^{10}$

Thus we might reason that the plain meaning regime might save some of the substantial costs of researching legislative history. But it would also incur new costs. Parties, for example, might hire linguistic experts to testify or write amicus briefs on the textual meaning of critical passages. ${ }^{11}$ Which set of costs would be higher? There is no way to know in the abstract. The best way to answer the question would be to conduct the right experiment. ${ }^{12}$ If we had sufficient resources we could, for example, set up two court systems identical in every relevant respect except that each would use a different rule about legislative history. Running the same cases through them under the different interpretive rules would supply valuable data about costs. But we can't afford that, and even if we could the amount expended to conduct the experiment might dwarf the amount saved by choosing the cost-minimizing doctrine concerning legislative history.

The alternative to direct experimentation is to fall back upon comparative and historical empiricism. A comparative project could attempt to estimate the costs of adjudication in state courts that do and do not use the plain meaning rule. A historical project could attempt to estimate the costs of adjudication in statutory cases decided in the federal system before and after 1940, the year in which the Supreme Court abandoned the plain

9 Compare Caminetti v United States, 242 US 470, 490 (1917) (announcing plain meaning rule), with United States $v$ American Trucking Associations, 310 US 534, 542-44 (1940) (ruling legislative history admissible whenever it provides interpretive aid).

${ }^{10}$ For a similar point in the context of bankruptcy law, see Douglas G. Baird, Bankruptcy's Uncontested Axioms, 108 Yale I J 573, 574-75 \& n 7 (1998).

1 See, for example, Brief Amicus Curiae of the Law and Linguistics Consortium in Support of Respondents, United States v X-Cite-Ment Video, 513 US 64 (1994), available on Westlaw at 1993 US Briefs 723.

${ }_{12}$ See Franklin M. Fisher, Multiple Regression in Legal Proceedings, 80 Colum L Rev 702,705 (1980) ("If we could make controlled experiments, it would be relatively easy to quantify the relationship being investigated."). 
meaning rule..$^{13}$ But the data are spotty, and it will be too difficult to trace effects to their proper causes. Suppose that the historical project found a dramatic rise in litigation fees paid to the Supreme Court bar in statutory cases after 1940. Would that show that the total costs of adjudication are higher in a regime with unrestricted use of legislative history? Not necessarily, or even probably. Aside from the point that litigation costs are only one component of the total costs of adjudication, we would have to collect data sufficient to test a broad range of competing hypotheses as well: perhaps legal fees for all cases rose at the relevant time, perhaps legal fees rose in statutory cases for reasons unrelated to the use of legislative history, and so forth. The question might turm out to have a complexity, and resistance to empirical closure, on the same order of magnitude as the deterrent effect of the death penalty.

This is certainly not to insist that all the empirical questions relevant to the debate over interpretive formalism are resistant to closure, or that empirical questions ought not be studied. As Beth Garrett rightly points out, there is surely a nontrivial range of questions amenable to research, ${ }^{14}$ and having some data is usually better than having no data. The bite of the closure problem is to dilute the promise of empiricism for prescriptive legal scholarship. Scholars often desire to make recommendations to courts and other interpreting institutions about whether particular doctrines, or even the whole interpretive system, should be given a formalist or nonformalist cast. But courts, unlike the academy, cannot indefinitely await the conclusive study; they must choose doctrines today that will govern the disposition of cases today and tomorrow. If many of the relevant empirical questions cannot be closed in the short or medium term, then courts will lack the information needed to assess the plausible empirical claims underlying both formalist doctrine and its antiformalist competitors. ${ }^{15}$

To be sure, judges might choose a rule and then hope that deciding a stream of future cases under that rule will provide them with information that will enable them to update their original choice. But updating will by no means prove a cure-all. The stream of future cases will provide information only about the rule chosen. The question of rule choice, however, is comparative, and there will be no new information about the rule not cho-

\footnotetext{
${ }^{13}$ See American Trucking Associations, 310 US at 542-44.

${ }^{14}$ Garrett, 34 Tulsa L J (forthcoming 1999) (cited in note 4).

is See Thomas W. Merrill, Institutional Choice and Political Faith, 22 L \& Soc Inquiry 959, 970 (1997) (making this point about empirical approaches to institutional choice).
} 
sen. Switching to the originally rejected rule in order to generate information about that alternative is possible, but highly destabilizing. Even worse, the institution that chooses the rule may not itself receive the updated information. The Supreme Court may choose between possible doctrines based on the justices' empirical hunches, but the lower courts must necessarily handle the bulk of the subsequent cases, and if the doctrine chosen is uniformly applied by the lower courts the Supreme Court will probably not revisit it no matter how bad it is on other grounds.

In short, there are good reasons to believe that, across a range of issues, the empiricist project Sunstein outlines will have to choose doctrines under conditions that prevent empirical questions from coming to closure, at least in the short term or at acceptable cost. Perhaps something like the following situation captures the challenge for empiricists: The judges on a court of last resort are attempting to decide whether (and when) legislative history should be admissible in statutory cases. Some of the judges believe that legislative intent is the authoritative criterion of legitimacy in statutory interpretation, and that against that benchmark error will be more prevalent in a regime that excludes legislative history. Other judges stipulate for argument's sake to the use of legislative intent as the criterion of legitimacy; they believe, however, that even on intentionalist premises error will be more prevalent in a regime that consults legislative history. Each group of judges can supply plausible empirical speculations in support of its view, but neither can conduct experiments, and neither can achieve closure on the empirical questions through comparative or historical empiricism - or at least cannot do so quickly enough, and cheaply enough, to decide whether legislative history should be admissible. What should the judges do?

\section{CHOOSING INTERPRETIVE RULES UNDER EMPIRICAL UNCERTAINTY}

The nub of the closure problem, then, is how, in the face of severe empirical uncertainty, to approach the empirical questions that determine whether interpretive doctrine should be given a formalist or nonformalist character. The pervasiveness of the closure problem does not necessarily doom the empiricist project to futility. Courts and commentators implicitly use a range of strategies to choose among plausible empirical assumptions when empirical questions cannot be closed out in the short or medium term. 


\section{A. Allocating Burdens}

One popular strategy is to allocate the burden of empirical uncertainty on particular questions to one side or the other. Burden allocation takes many forms. ${ }^{16} \mathrm{~A}$ common variant is to allocate the burden of empirical persuasion to those advocating a change in the legal status quo; unless the existing rule is demonstrably inferior to some possible substitute, the existing rule will prevail. Sunstein's review of Justice Scalia's book on interpretation illustrates the approach. ${ }^{17}$ After noting that the choice between formalist and antiformalist approaches to legislative history turns upon a range of uncertain empirical and predictive judgments, Sunstein argues that "in light of our longstanding traditions [that license the use of legislative history], a dramatic shift of the sort proposed by Justice Scalia [who would exclude legislative history] bears a heavy burden of justification, and he has not met that burden here."

How convincing is the burden allocation strategy? In the particular example, Sunstein's conclusion seems contestable. The most recent work suggests that the Court's use of legislative history rose slowly between $1892^{19}$ and the Second World War, reached an apogee during the Burger Court, declined sharply after Justice Scalia joined the Court, and is now rising slowly again. ${ }^{20}$ In the Court's 1996 Term, 51 percent of the Court's majority opinions in statutory cases did not use legislative history. ${ }^{21}$ The most that can be said about legislative history is that it was hardly ever used before $1892^{22}$ (about half of our national history), that its use has waxed and waned since then, and that nowadays it is used about as often as not. So there just is no settled tradition with respect to legislative history, and no current status quo.

1s See generally Richard H. Gaskins, Burdens of Proof in Modem Discourse (Yale 1993). See also Richard A. Posner, The Problems of Jurisprudence 203-19 (Harvard 1990) (discussing mechanisms, including burdens of proof, by which law sidesteps factual uncertainty).

${ }^{17}$ Cass R. Sunstein, Justice Scalia's Democratic Formalism, 107 Yale L J 529, 548 (1997).

${ }^{18} \mathrm{Id}$ at 548.

19 The date of Church of the Holy Trinity $v$ United States, 143 US 457 (1892), the Court's first important use of legislative history.

${ }^{20}$ See Jane S. Schacter, The Confounding Common-Law Originalism in Recent Supreme Court Statutory Interpretation: Implications for the Legislative History Debate and Beyond, 51 Stan L Rev 1, 9-17 (1998); Lawrence M. Solan, Law, Language and Lenity, 40 Win \& Mary L Rev 57, 97-102 (1998).

21 Schacter, 51 Stan L Rev at 15 (cited in note 20).

22 See Vermeule, 50 Stan L Rev at 1836 n 14 (cited in note 6) (discussing the Court's limited use of legislative history before Holy Trinity). 
This objection has a more general significance: it shows that the burden allocation strategy often does no more than push the closure problem back a step. The character of the status quo will often be highly contestable, and the more energy courts and commentators must invest in deciding what it is, the sillier the enterprise becomes; why not just spend that time figuring out the best rule? The limiting case of this problem occurs when none of the alternative rules is currently in place, because a novel issue of interpretive doctrine has come to the Court's attention. These situations are not infrequent-in recent memory the weight to be afforded presidential signing statements, for example, became a significant issue only during the Reagan Administration ${ }^{23}$-and the burden allocation strategy supplies little help in their solution. ${ }^{24}$

\section{B. All-Else-Equal Strategy}

The burden allocation strategy illustrates an approach that might be called the "all-else-equal" strategy. In the case of burdens that protect the status quo, for example, the burden-shifter reasons that the costs of transition from the status quo to the proposed alternative are clearly positive and that the comparison of other costs and benefits between the two alternatives is so speculative as to wash out to a tie-in which case the transition cost breaks the tie in favor of the status quo. This calculus implicitly assigns equal values to the other components of the total costs of the status quo and the proposed alternative. ${ }^{25}$

The same reasoning might be applied to other sorts of costs as well. Consider the following possible claim: The costs of research and litigation will clearly be lower if the interpretive regime excludes all legislative history than if the interpretive regime admits any legislative history. The comparison of other decision costs, error costs, and so forth between the two alternative

${ }^{25}$ See William Popkin, Judicial Use of Presidential Legislative History: A Critique, 66 Ind L J 699, 700-09 (1991).

${ }^{24}$ Extending the scope of the burden allocation strategy by analogical reasoning is possible. The role of presidential signing statements in statutory interpretation, for example, might be determined by analogy to their (prominent) role in treaty interpretation. But the relevance of the analogy will often be subject to legal and factual debate-the president's role in treaty formation, for example, differs importantly from his role in the legislative process-and the proper allocation of the burden will once again become as contestable as the underlying question.

${ }^{25}$ It is thus an application of the principle of insufficient reason, which instructs decisionmakers under uncertainty to assume that unknown probabilities are equal. See $R$. Duncan Luce and Howard Raiffa, Games and Decisions: Introduction and Critical Survey 284-85 (John Wiley 1958). 
regimes is speculative, or even completely indeterminate. If those are the only two alternatives, then courts should exclude all legislative history.

Does this sort of reasoning make sense? Maybe not. On one view, deciding on this sort of basis is irrational. The values of the other variables are unknown in the alternative regimes, but that does not mean they are equal. Rather, the unknown costs of one regime may well dwarf the unknown costs of the other. The allelse-equal strategy is akin to trying to pick the larger of two numbers by choosing the one with the larger digit in the second decimal place, even if one knows nothing about the digit in the first decimal place. ${ }^{26}$ But the all-else-equal strategy retains a nagging force. If we know that one component of cost is higher in one regime than the other, and we really can't figure out much else, on what other basis could we decide? On this view, then, the plausible belief that a regime excluding legislative history will minimize litigation costs may carry us a long way towards interpretive formalism in light of the difficulty of the other questions.

\section{Professional Consensus}

Another popular strategy is to turn to professional consensus, in the hope that many speculative assessments of unmeasurable costs will prove better than one or a few. William Eskridge has used this sort of argument to critique textualist approaches to statutory interpretation, pointing out that the great bulk of academic studies, for example, have concluded that textualism performs rather poorly. ${ }^{27}$ As with the burden allocation approach, the idea seems fine in the abstract, if dubious in the particular application. Both rational choice and Burkean approaches suggest that deference to a developed consensus is often a sensible move for actors who themselves lack the information necessary for decisionmaking; moreover, consensus reduces the variance of opinions and thus dampens the effect of extreme views. But relying upon a consensus on such grounds assumes either that the members of the reference group have formed their views independently of each other, or that the circle of consensus possesses better information than the decisionmaker. In the choice of statutory interpretation doctrines neither condition may hold. Esk-

\footnotetext{
${ }^{26}$ See Jon Elster, Nuts and Bolts for the Social Sciences 32-36 (Cambridge 1989).

"See William N. Eskridge, Jr., Textualism, The Unknown Ideal?, 96 Mich L Rev 1509, 1551-52 \& nn 151-52 (1998).
} 
ridge himself has done one of the very few extended empirical studies relevant to that choice, ${ }^{28}$ the other studies are qualitative and analytical, and typically illustrate their points with a handful of famous, and frequently discussed, hard cases. The current academic consensus against textualism rests upon the shakiest of empirical foundations.

\section{CONCLUSION}

The empiricist project is a sensible long-term investment. There are undoubtedly factual questions that are both relevant to the choice between interpretive formalism and antiformalism and also answerable by the usual methods of empiricism. But judges must choose doctrines now, and empiricism probably cannot close out enough of the relevant questions quickly and cheaply enough to provide much aid in the short and medium term. This need not entail rejecting the empiricist project, for empiricism is not so much desirable as inevitable, at least across the broad range of questions in which any particular theory of interpretive legitimacy proves compatible with several candidate doctrines. Within that range, explicit or implicit assumptions about empirical issues will determine which choice is actually made. But the difficulty of closing out the relevant empirical questions does entail that in the short and medium term the empiricist project will have to lean heavily upon a repertoire of weak strategies for choosing doctrines under conditions of severe empirical uncertainty. The prospect is a modest one, but it is all we have.

\footnotetext{
${ }^{28}$ See William N. Eskridge, Jr., Overriding Supreme Court Statutory Interpretation Decisions, 101 Yale L J 331 (1991).
} 


\title{
SYMPOSIUM: FORMALISM REVISITED
}

\author{
FORMALISM IN COMMERCIAL LAW
}

The Questionable Empirical Basis of Article 2's Incorporation Strategy:

A Preliminary Study Lisa Bernstein 710

The Tentative Case Against Flexibility in Commercial Law Omri Ben-Shahar 781

Confusion about Custom: Disentangling Informal Customs from Standard Contractual Provisions. Richard A. Epstein 821

Eroding Entitlements as Litigation Commitment............................................. Ian Ayres 836 The New Formalism in Contract ........................ David Charny 842 Moderated by Daniel R. Fischel 